\title{
Report on Self-Management of Mental Wellbeing Using Bonsai as an Ecotherapeutic Art Tool
}

\section{Caroll Hermann}

Department of Psychology, University of Zululand, KwaDlangezwa, South Africa Email: hermannc@unizulu.ac.za

ORCID ID: 0000-0002-7224-8297

\begin{abstract}
Objective: The study investigated the benefit of practicing the art of bonsai and the wellbeing of practitioners. The art promotes relaxation, focus and art therapy that can have personal and emotional value in a self-help setting. When the bonsai tree is used as a healing object, it may improve the ability of the bonsai practitioner to adapt to adverse and stressful life events, such as the present global COVID-19 pandemic. Method: International bonsai artists $(n=255)$ participated in a study that examined the effect their bonsai had on their mental well-being. Semi-structured interviews were conducted with bonsai artists answering the question: "How has bonsai helped you? ”. Results: Most participants acknowledged that being able to take care of their bonsais affected their mood in a positive manner. Discussion: Although the participants did not report overall improved mental health, participants expressed an improvement in their mood when being able to work on a bonsai tree. Conclusion: These findings are significant in that it can be useful in as a preventative and restorative manner in the mental well-being of people who practice the art.
\end{abstract}

\section{Keywords}

psychotherapy; mental health; self-management; intervention; art therapy; bonsai 


\section{Introduction}

Creative processes are powerful mechanisms for the release of inner emotions (Styliano \& Havran, 1998). Together with Jungian principles such as self-awareness, transformation, and actualisation, and using rituals, may have the benefit of purging the client from pain or painful events whilst working on a bonsai. Art not only contributes significantly to analytical psychology but also manifests as a personal expression or form of something more universal that exists within every person (Whitmont \& Kaufman, 1973).

Penzes, van Hooren, Dokter, Smeijsters and Hutschemaekers, (2014) state that the art product (and this case, the bonsai) is an object of transference and therefore represents the unconsciousness and psychological conflicts of a person. The art object then becomes of value to the client and the therapist.

Psychotherapy is an interpersonal intervention by trained therapists to aid in serious challenges in daily activities (Whitfield \& Williams, 2003). Gardening (being in nature) has is known as a great relaxer and beneficial to mental health. Wolff and Flora (2010) state that spending time in nature help improve mental fatigue by soothing and renovating the mind. Being active outdoors (gardening) contributes positively to ease the stressors of dementia, stress, and depression, and can improve cognitive functioning (Wolff \& Flora, 2010).

Self-help or self-management is defined as methods, skills or strategies by which people direct their activities to achieve optimal mental health well-being (Potash et al., 2013; Yeung et al., 2010). The principles of self-management include empowering patients through shared decision making and promoting self-efficacy through self-management education (Yeung et al., 2010). In a time where social distancing and isolation have become keywords, self- 
management methods may increase access to more people. It has the potential to empower people and it may enhance the efficacy of standard treatments (Yeung et al., 2010).

The benefits of being in nature are beyond dispute. Spending time with nature can, for instance, relieve stress in children and adults, connections to families and loved ones (Weissman, 1971). Weissman (1971) further posits that the creative person has a relationship with his created object from which they are inseparable. The artist and the art object can be better understood when more is known about the origins and meaning of the created object. This study also found that the created object has cathartic characteristics that has its origin in "early infantile ... relationships" and being so, irrevocably binds the artist to the creation (Buchalter, 2004; Weissman, 1971, p.1).

Various art mediums are centered around stress management, ie., the reduction of anxiety and tension by using various senses, such as tactile, visual, olfactory and auditory (listening to nature sounds around you). When energy is used in a creative manner, tension is released (Buchalter, 2004). A study employing Ulrich's theory of supportive design found that when participants imagined elements of positive distraction such as photographs or representation posters of nature. Past research demonstrated a preference for scenes from nature (Audia et al., 2014).

\section{Art Therapy}

Art therapy is an established tool in psychology as a useful intervention method. Bonsai can serve as a transitional (artful) object as part of the psychoanalytical process. Psychoanalysts regard the relationship between the artist and the objects being created objects as inseparable from the concentrated mental energy. This inseparable relationship that stays with the artist 
could be further explained if the subjective idea or origin of the created object (i.e. bonsai) was shared with other people (Weissman, 1971).

It is when the artist in in a creative state and the contextual objects become representative of (events in) the artist's life. Much of Weismann's (1971) work refers to Winnicot's flexible value of the "potential space" when discussing to the transitional area as "that which lies between fantasy and reality" (p1). The type of potential space includes the "play space", in this instance, the "Bonsai-en" (the bonsai garden), the "transitional object" refers to the tree and the pot, the "analytic space" may represent expression phenomenologically, and the area of creativity refers to processes within the artist.

Wrathall (2011) state that "what art does is philosophically significant" and that art can function in a way to understand the lived life of the artist. The study was specifically interested in how the artist deals with having to discuss the meaning of the artwork directly and narrating it to the therapist. Thus, phenomenologically, the artist aspires to "resolve philosophical questions" about the art (in this case the bonsai) (Wrathal, 2011).

\section{Ecotherapy}

Ecotherapy is defined as "psychotherapeutic activities (counselling, psychotherapy, social work, self-help, prevention, public health activities) undertaken with an ecological consciousness or intent" (Jordan \& Hinds, 2016, p.14) in a natural setting or using nature as part of the process. Previous studies found that taking therapy outdoors, has positive implications for mental health and well-being by reducing stress, depression, rehabilitation and even dementia (de la Motte-Hall, 2015; Jordan \& Hinds, 2016). Another study showed 
that hospitals beds that faced nature reduced recovery time and visible pot plants while working or studying can reduce anxiety and depression.

Nature-guided therapy can be used as projective methods to mirror the themes of "birth, growth, death and renewal" to life's psychosocial transitions, amongst other inner worlds of the client (de la Motte-Hall, 2015).

Robinson (2005) suggests that one questions one's own place in the world and examining one's contribution. Ecopsychology is conceived in the soul, and needs time and attention, summarised as being about "home, soul and story" (p.40).

Art forms, (such as bonsai) embraces all that is in nature, such as trees, rocks, water, etc. (Brody, 2001) and the artist can "be" in nature in his own space with the philosophy or the "spirit of bonsai" (the love for bonsai and enlightenment through nature) (Brody, 2001; Weissman, 1971). During the process of the envisioned idea (of the bonsai), the artist enters into introspection, and results in a state of pure calm and inner silence. Later, when this has been achieved, creativity can take place. Assagioli (2010) claims that the significance of challenges, become clearer during this state which is perceived as enlightenment or clarification of challenges and situations. When these challenges are viewed from a different perspective, solutions become clearer. When viewing the created object, peace is experienced as self-determined and happiness and pleasure, peace, grace, and power can be felt (Assagioli, 2010; Weissman, 1971).

\section{Theoretical underpinnings}

More and more interest is shown in nature-based therapy due to contact with nature can relief stress. Although several studies reported positive effects of therapy in and of a nature kind, few theoretical models exist. Kaplan and Kaplan's attention restoration theory (Kaplan \& 
Kaplan, 1989; Oh et al., 2020) is one of the core theories focused on nature's ability to relief stress. Wilson's biophilia hypothesis (love of life) and the topophilia (love for places) hypothesis (Oh et al., 2020) forms the basis of Kaplan and Kaplan's attention restoration theory. Affiliations and positive feelings are formed with the natural environment, such as stones (suiseki) and living elements (plants) through learning.

Oh, et al., (2020), bases their model of nature-based therapy on six steps or categories, namely: stimulation; acceptance; purification; insight; recharging and change in order to improve health and quality of life. Several studies support theories of recovery in nature, by either spending time in it or just viewing it.

\section{Bonsai}

Bonsai is a Japanese word that means "tree in a pot" and is an art practiced on all the continents of the world today (Koreshoff, 1997). It is generally accepted that the art of bonsai first started in China and was later perfected by the Japanese. It is considered to be a living art by all who practice it. Although the many bonsai artists are aware of the healing and soothing properties of bonsai, no formal studies have been conducted before.

Chinese bonsai styles are steeped in myths and legends and often resemble dragonesque and animal like trunks and roots. Japanese artists prefer to simulate the natural beauty of trees and was introduced by Zen Buddhists (Kimura, 2007).

Very few studies on the benefits of practicing or viewing specifically bonsai exist. A study in 2017 examined the psychophysiological effects of viewing bonsais on male spinal cord patients (Ochiai et al., 2017) and found a significant decrease in psychophysiological stress symptoms. 


\section{Materials and Methods}

Bonsai focus groups were invited to complete questionnaires and to answer the question: "How has bonsai helped you?" over a 30 day period in an online study in 2015. Finally, the correspondence was analysed using a thematic analysis approach. Participants were required to complete an online questionnaire based on demographics and their general interest in bonsai, designed by the researcher, as well as a discussion around the question: "What does bonsai mean to you?"

\section{Sample:}

International bonsai artists $(n=255)$ took part in the study via online questionnaires and/or Skype or email conversations in unstructured interviews with the researcher which included personal narratives and existing autobiographies made available to the researcher. Many of the participants reported various mental, physiological and social symptoms, such as stress, depression, bereavement, pain management and autism traits.

\section{Data Analysis:}

Themes were drawn from the transcribed narratives and interviews using a thematic analysis approach using SPSS V25 and NVIVO 12. During analysis codes were used and themes were established using a codebook. Segments of texts were tagged and sections with similar content were sorted into different categories for simple classification which were then arranged into major themes.

\section{Ethical considerations:}

Permission was obtained from the Research Ethical Committee of the University of Zululand, (UZREC 171110-030-RA Dept.2015/85) as well as informed consent from all participants. 
Confidentiality and anonymity were ensured by encoding all material. Participants were informed that they could withdraw at any stage. All research protocol was observed.

\section{Results}

The demographic results indicated that 255 participants 201 (78.82\%) were male and 54 $(21.18 \%)$ females although a comparatively equal split of male and females were invited to participate. A small number of respondents, $(0,8 \%)$ were below the age of 25 , and $37,3 \%$ between 26 and 40. The biggest proportion of participant fell in the 41 to 60 age gap and $9 \%$ over the age of 61 .

One participant (0.4\%) spent "hardly any time" in their bonsai garden, 51, (20\%) stated that they spend "some time per week" and $203(79,6 \%)$ said that they are daily in their bonsai garden. Participants were required to self-evaluate their mood and 117, $(45,9 \%)$ reported that they were "generally happy", 99 or 38,8\% reported "minimal feelings of depression", 22 or $8,6 \%$ reported "mild depression and 17 reported 'moderate depression'. No cases of severe depression were reported. 


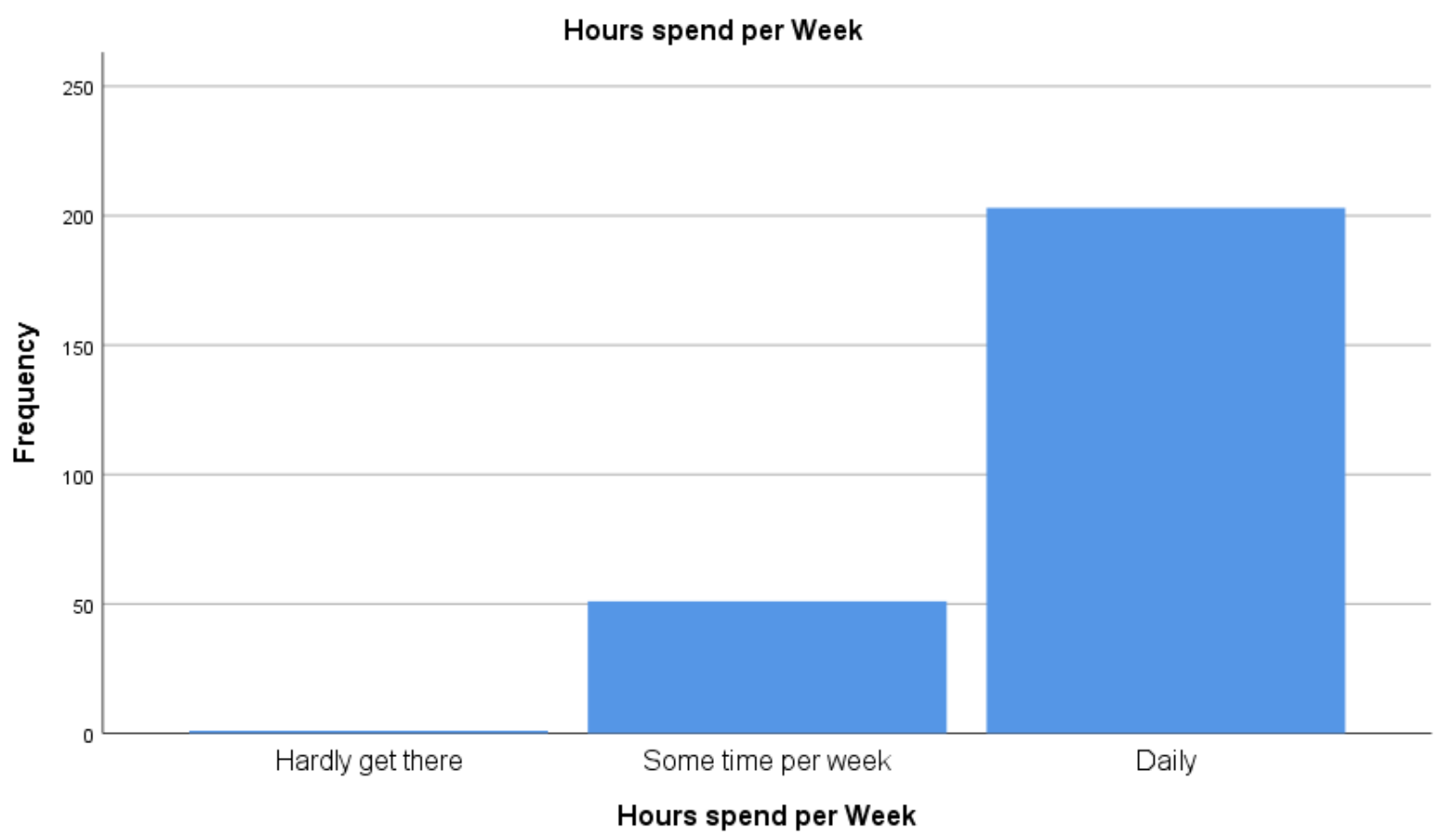

Table 1: Time spent with bonsai (working or viewing) 


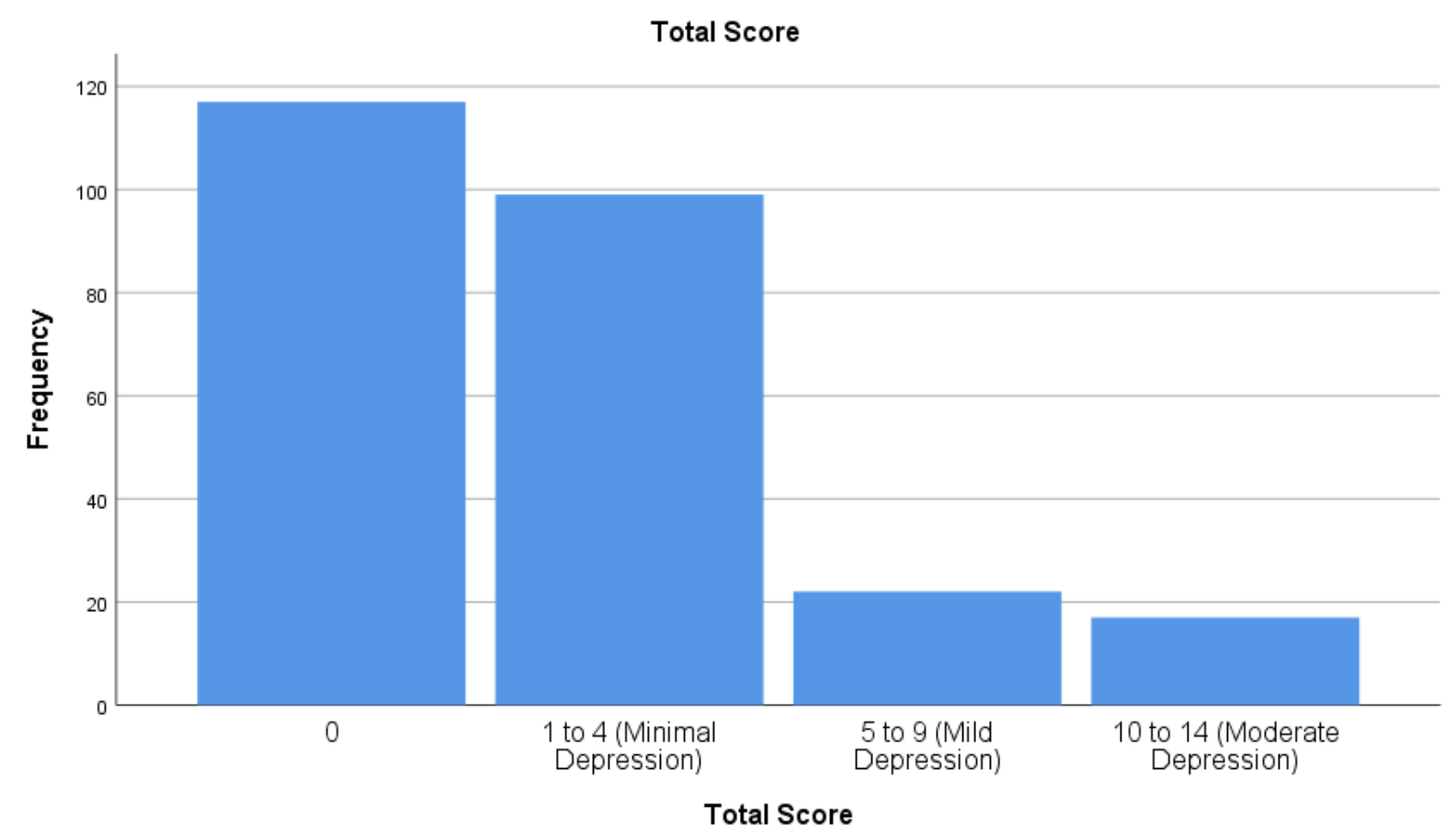

Table 2: Self evaluation of depression by participants.

The majority of participants, $(98,8 \%)$ responded that being able to work with their bonsai had a positive and relaxing effect on their state of mental health and 95, 7\% declared that not not working on their bonsais, had a negative effect on their mood. One participant reported that working on bonsai was not relaxing, was a bonsai vendor and therefore made a living out of selling bonsai.

Subjective correlative analysis of content refers to analysing data that is collected from participants during correspondence. All conversations were transcribed, and all other written communications (either email correspondence or participant CV's) were organised in an encodable MS Word document format. 
"Thematic analysis", according to Braun and Clarke (2006), involves a procedure of classification, analysis, and the reporting of detailed word patterns and/or rich word themes set in the data that was collected. The focus of this analysis was to identify and interpret the healing aspects of the research topic.

Although thematic analysis is frequently applied during investigation of qualitative data, Braun and Clarke (2006) stated that researchers should envisage it as a foundational tool due to its diversity and complex nature. Braun and Clarke (2006) asserted that due to the flexibility of thematic analysis, it becomes exhilarating to discover themes and concepts that are found throughout the interviews.

Thematic analysis differs from other analytical approaches in that the process attempts to describe common occurrences across qualitative data such as "thematic" discourse interpretation, or thematic decomposition analysis, and grounded theory, as oppose to explaining differences in opinions.

\subsection{Thematic Analysis}

\begin{tabular}{|l|l|l|}
\hline Global Theme & Organising Themes & Basic Themes \\
\hline $\begin{array}{l}\text { Experiences and perceptions } \\
\text { on the meaning of the art of } \\
\text { bonsai }\end{array}$ & Nature & soil \\
\cline { 3 - 3 } & & Bonsai \\
\cline { 2 - 3 } & & Tree \\
\hline
\end{tabular}




\begin{tabular}{|l|l|l|}
\hline \multirow{2}{*}{ Spiritual } & Religion \\
\cline { 3 - 3 } & & Silence \\
\cline { 3 - 3 } & & Time \\
\cline { 3 - 3 } & Cognition & Concentration \\
\hline & & Controlling \\
\cline { 3 - 4 } & & Rituals \\
\cline { 3 - 4 } & & Mental alertness \\
\hline
\end{tabular}

\section{Table 3: Thematic Schemes}

3.1.1. Theme 1 Nature - with sub-themes of bonsai, tree, and soil emerging as important components. "I just concentrated on my tree of choice for a long time. I channeled my imagination toward attempting to design it. When the idea came to me, I started to work"; "...starting by cleaning first the soil surface then the pot and then the trunk and branches. Only after all this do I take a relaxed look at the tree and decide how to proceed and whether or not to change anything."; "...it has made me more aware of the cultural needs of the flora I see around me, and it has helped me learn to think as a steward of nature rather than a simple user."; "With regard to ecological wellbeing, growing bonsai has made me more aware of the necessity to maintain the growth of trees, jungles and our surroundings."; 
"Growing bonsai has made me love nature more."; "The bonsai was formerly just a natural plant growing wild as a friend of snakes, insects and other low-level animals. Now it (the bonsai) is trained to be a civilised creature".

3.1.2. Theme 2 Spiritual - Sub-themes religion, God and Zen were evident. "Many feel that being able to spend time with your bonsai, is a divine experience in which every decision to cut back, nip or leave to develop is a reflection of the artist's spirit and personality."; "Negative space resonates within my soul to a certain degree but I focus more on the general 'feel' of the tree than on the individual components (as with life)."; "Growing bonsai is really a good means by which to train one's spirit."; "A small pot and minimal nutrient in the whole life is a good method of self-discipline and control of our desire. Consistency in controlling desire is a means to attaining a higher spiritual level."; "All of this will enable the tree to become holier in the sense of its spirituality, which will, in turn, allow it to become a higher creature in its next life; an animal or even a human being. The bonsai artist will also advance to a better level due to the discipline and his or her love shown to the trees...."; "This attention and tedious work carries me to a state where I just do it and forget about the rest of the world. I let my thoughts roam while I do the work. I often forget about time and space. This is called meditating. While being part of Zen Buddhism it can very well be done by an ordinary European without any religious or cultural connection with Asia."; "Object lessons found in bonsai, reflect, to a certain extent, God's dealings with us. For example, sometimes I'll remove a perfectly healthy and visually attractive branch from a tree, simply because it doesn't conform with my design for that tree because I'm the artist. God is a much better Artist than I am, and His designs are exactly right. Remembering that makes trust that much easier in difficult situations."; "In my past 
life, my soul was in a baobab. My soul still lives in a Baobab, even today"; "I respect nature as it reflects God's face".

3.1.3. Theme 3 Flow - silence, time and concentration emerged as sub-themes, "Negative space is very important for correct balance. As in life, you need the bad to place the good in perspective."; "I find this to be key, as I need silence in which to 'lose myself' when working on my trees."; "Silence allows communion with my trees and results in better concentration."; "Yes, I valued the silence, especially when I was still working. It was wonderful to return from work and concentrate on my trees with no interruptions or other people who needed attention. Very relaxing."; "When creating a tree to imitate a tree in nature, one becomes 'aware",; "This attention and tedious work carries me to a state where I just do it and forget about the rest of the world. I let my thoughts roam while I do the work. I often forget about time and space. This is called meditating. While being part of Zen Buddhism it can very well be done by an ordinary European without any religious or cultural connection with Asia."; "Yes, a desire to reduce our pain or to direct our concentration away from a painful thing is normal."; "weeding my bonsai pots, helps me to relax."

3.1.4. Theme 4 Cognition - sub-themes revolved around controlling, rituals, mental alertness. "We have to prune the top section of the tree regularly so as to force the nutrient to the lower part. It is an example of controlling the natural tendency in order to achieve a good result."; "To begin working without the cleaning ritual makes me feel uncomfortable because I could possibly overlook any number of important things."; "This attention and tedious work carries me to a state where I just do it and forget about the rest of the world. I let my thoughts roam while I do the work. I often forget about time and space. This is 
called meditating. While being part of Zen Buddhism it can very well be done by an ordinary European without any religious or cultural connection with Asia."; "Having to concentrate when shaping or styling a tree, or keep your mind active when handling a problem tree helps one to stay mentally alert and sharp."

3.2 Sentiment throughout narratives remained mainly positive. "I find joy in tending to my own trees and have shown my collection to but a few people."; "It helped me to overcome major (spinal) trauma in a positive way"; "I felt that it brought many things together for me."; "Very relaxing."; "happy" and "peaceful moments", "far better than spending time in social bonsai gatherings"; "At times, I do not find it stress-relieving. If we have hail or frost, my trees can die. I can never go on holiday. This is my bread and butter."; "Whenever I am sad or depressed, I go to my trees - and my mood shifts."

\section{Discussion}

The purpose of this study was to determine whether the art of bonsai has an effect on the mental well-being of people who own bonsai trees. The study provided validation that working, styling, designing and caring for bonsai and other activities in and around bonsai, such as trimming, weeding, watering might impact the capacity of a bonsai artist to adjust to negative life events. Results concluded that bonsai activities had a direct effect on mood adjustment, while creating a platform for spirituality. All participants, bar one, declared that bonsai activities contributed to their mental wellbeing. The one person who felt that bonsai did not contribute to mood or relaxing, made a living out of selling bonsai and was therefore not a hobby.

Participants who reported feeling minimal to moderate depression, also stated that their mood improved when spent with their bonsai. This is evident in Table 1 and 2 that the more time 
participants spent with their bonsai, the more their mood improved. This is in agreement with the study by Oh, et.al., (2020) who also found that nature-based therapy improved the mood of people who spent more time with and in nature.

4.1. Theme 1 Nature: It is evident that all the participants enjoyed time spent in nature and with their trees. Humans have a fundamental need to be in nature and have to take an active nurturing role for oneself (Robinson, 2005). Through connecting and reconnecting with the natural world humans can be healed (Robinson, 2005). Nature becomes the place where the therapy room used to be. Buzzel, (2005) claims that being outside, helps a client to slow down and focus on what is needed to heal. "I just concentrated on my tree of choice for a long time." It is evident in the responses that participants have a deep connection to nature, "it has helped me learn to think as a steward of nature rather than a simple user." Participants share a deep love and concern for all in nature "With regard to ecological wellbeing... maintain the growth of trees, jungles and our surroundings."

4.2 Theme 2 Spiritual: Bonsai are often viewed as objects of spiritulism due to the early Zen Buddhist history it shares. Kimura (2007) states that "the act of creating bonsai...by itself is a contemplative, meditative exercise - a practice of Zen" (p.21) and is seen as a "celebration of nature and the healing powers of an intact environment". "All of this will enable the tree to become holier in the sense of its spirituality, which will, in turn, allow it to become a higher creature in its next life; an animal or even a human being. The bonsai artist will also advance to a better level due to the discipline and his or her love shown to the trees...."; "I let my thoughts roam while I do the work. I often forget about time and space. This is called meditating. While being part of Zen Buddhism it can very well be done by an ordinary 
European without any religious or cultural connection with Asia."; "Object lessons found in bonsai, reflect, to a certain extent, God's dealings with us"

4.3. Theme 3 Flow: Kimura (2007) feels that bonsai philosophy can be compared to Daoism by learning to go with the flow, you allow your mind to function naturally and thereby unleashing creative power. "I find this to be key, as I need silence in which to 'lose myself' when working on my trees." "When creating a tree to imitate a tree in nature, one becomes aware" and thereby being in this state of "awareness" one tunes into the rhythm of nature and the interrelatedness of what is around us. "forget about the rest of the world. I let my thoughts roam while I do the work. I often forget about time and space.” By forgetting about all else, seeks to liberate the mind and to relax, ". weeding my bonsai pots, helps me to relax."

4.4. Theme 4 Cognition: Jordan and Hinds (2016) claim that ecotherapy offers insight into thoughts, emotions, etc and that these mental processes are a product of ecological interactions. By developing a therapeutic setting outside of a therapy couch sharpens awareness, offer tools and embody connections (p.33; Jordan \& Marshall, 2010). Oh, et.al., (2020) found in their study that participants' positive nature experience varied between one and 'many' visits and results indicated that health promotion was more effective if the nature source was closer to home and visited more frequently than occasionally further away from home. All the participants had bonsai gardens at their homes and this contributed to better mood management by having it close by. "We have to prune the top section of the tree regularly so as to force the nutrient to the lower part" and "Having to concentrate when shaping or styling a tree, or keep your mind active when handling a problem tree helps one to stay mentally alert and sharp." 
4.5 Sentiment: All participants, except for one, ("I do not find it stress-relieving. If we have hail or frost, my trees can die. I can never go on holiday. This is my bread and butter.”) maintained a positive sentiment in their responses. Sheldon and Lyubomirsky (2004) state that happiness is central to mental health and has additional benefits such as enhanced physical health, ("It helped me to overcome major (spinal) trauma in a positive way") superior coping skills, ("I find joy in tending to my own trees") and reduced mental health challenges ("Whenever I am sad or depressed, I go to my trees - and my mood shifts.")

\section{Conclusions}

The study was limited to serious bonsai growers and did not include people who have never attempted the art. This, however, opens the scope for further studies. While results of this study suggested that being engaged in bonsai activities could have direct and indirect positive influences on the individual's mood regulation, further study is recommended with a nonpracticing group.

The findings of this study has implications for self-help platforms and access to isolated and remote areas, empowering the client in a creative manner with no pre-existing skill set needed. Bonsai practice can serve as a preventative as well as restorative measure in the mental well-being of people who practice the art. 
Funding: This research received no external funding.

Conflicts of Interest: The author declares no known conflict of interest.

\section{References}

Assagioli, R. (2010). Meditation Triangle Units Some Collected Works of. September.

Audia, C., Andrade, C., \& Devlin, A. S. (2014). Stress reduction in the hospital room: Applying Ulrich's theory of supportive design. https://doi.org/10.1016/j.jenvp.2014.12.001

Brody, M. S. (2001). Paul Klee: art, potential space and the transitional process. In Psychoanalytic review (Vol. 88, Issue 3, pp. 369-392). http://www.ncbi.nlm.nih.gov/pubmed/11603258

Buchalter, S. (2004). A Practical Art Therapy. Jessica Kingsley Publishers. de la Motte-Hall, L. (2015). Gestalt therapy and Ecotherapy: the growing field of practice. Jordan, M. \& Hinds, J. (2016). Ecotherapy: theory, research \& practice. Palgrave McMillan.

Jordan, M., \& Marshall, H. (2010). Taking counselling and psychotherapy outside: Destruction or enrichment of the therapeutic frame? European Journal of Psychotherapy and Counselling, 12(4), 345-359. https://doi.org/10.1080/13642537.2010.530105

Kaplan, R., \& Kaplan, S. (1989). The Experiences of Nature: a Psychological Perspective. Cabridge University Press.

Kimura, A. (2007). The ancient art of bonsai. Wiley Publishing. 
Koreshoff, D. (1997). Bonsai: Its art, Science, History and Philosophy. Timber Press.

Ochiai, H., Song, C., Ikei, H., Imai, M., \& Miyazaki, Y. (2017). Effects of visual stimulation with bonsai trees on adult male patients with spinal cord injury. International Journal of Environmental Research and Public Health, 14(9). https://doi.org/10.3390/ijerph14091017

Oh, K., Shin, W., Khil, T., \& Kim, D. (2020). Six-Step Model of Nature-Based Therapy Process.: Discovery Service for University of Zululand. Internation Journal of Environmental Research and Public Health2, 17(685), 1-18. http://eds.a.ebscohost.com/eds/pdfviewer/pdfviewer?vid=1\&sid=cbc1f26e-741d-4d45bdc9-2aa44eaf3639\%40sdc-v-sessmgr03

Pénzes, I., van Hooren, S., Dokter, D., Smeijsters, H., \& Hutschemaekers, G. (2014). Material interaction in art therapy assessment. Arts in Psychotherapy, 41(5), 484-492. https://doi.org/10.1016/j.aip.2014.08.003

Potash, J. S., Ho, R. T. H., Chick, J. K. Y., \& Au Yeung, F. S. W. (2013). Viewing and engaging in an art therapy exhibit by people living with mental illness: Implications for empathy and social change. Public Health, 127(8), 735-744. https://doi.org/10.1016/j.puhe.2013.05.004

Robinson, L. (2005). Ecotherapy: Healing with nature in mind (L. Buzzel \& C. Chalquest (eds.)). Sierra Club Books.

Styliano, N., \& Havran, H. (1998). Thinking about therapy. Penguin Group.

Weissman, P. (1971). The Artist and his objects. INternational JOurnal of PsychoAnalysis, 52(4), 401-406. 
http://eds.a.ebscohost.com/eds/detail/detail?vid=0\&sid=7e2f6963-f414-4d64-81610d596b1be3dc\%40sessionmgr4006\&bdata=JkF1dGhUeXB1PXNzbyZzaXRIPWVkcy

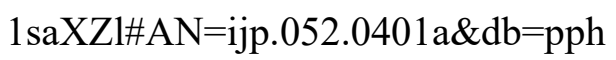

Whitfield, G., \& Williams, C. (2003). Evidence base for CBT in depression. 9(9), 21-30. http://apt.rcpsych.org/

Whitmont, E., \& Kaufman, Y. (1973). Analytical Psychotherapy. In Current Psychotherapies (pp. 85-112). Peacock Publishers.

Wolff, K., \& Flora, K. (2010). Mental Health and Function - a Literature Review. Green Cities: Good Health. http://depts.washington.edu/hhwb/Thm_Mental.html

Wrathal, M. (2011). Art and Phenomenology. In J. Parry (Ed.), Art and Phenomenology. Routledge.

Yeung, A., Feldman, G., \& Fava, M. (2010). Self-management of Depression: a manual ofr mental health and primary care professionals. Cambridge University Press. 